\title{
VP2 Gene-Based Molecular Evolutionary Patterns of Major Circulating Bluetongue Virus Serotypes Isolated during 2014-2018 from Telangana and Andhra Pradesh States of India
}

\author{
Ravali Thota $^{a}$ Vishweshwar Kumar Ganji ${ }^{a}$ Sharanya Machanagaria \\ Narasimha Reddy Yella ${ }^{a}$ Bhagyalakshmi Buddala ${ }^{a}$ Krishnajyothi Yadlapati ${ }^{b}$ \\ P.P. Rao ${ }^{c}$ Sushila Maan ${ }^{d}$ Narender S. Maan ${ }^{d}$ Divakar Hemadrie \\ Karam Pal Singh ${ }^{f}$ Kalyani Putty ${ }^{a}$ \\ aDepartments of Veterinary Microbiology and Veterinary Biotechnology, College of Veterinary Science, PVNRTVU,

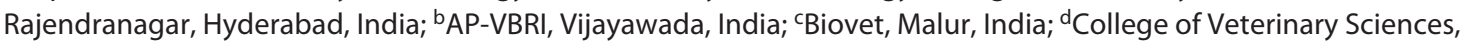 \\ LLR University of Veterinary and Animal Sciences, Hisar, Haryana, India; eICAR-NIVEDI, Yelahanka, Bengaluru, India; \\ fPathology Laboratory, CADRAD, ICAR-IVRI, Izatnagar, Bareilly, India
}

\section{Keywords}

Bluetongue · Phylogenetic analysis · Indian BTV isolates ·

Topotypes

\begin{abstract}
Introduction: Bluetongue disease is an economically important viral disease of livestock caused by bluetongue virus (BTV) having multiple serotypes. It belongs to the genus Orbivirus of family Reoviridae and subfamily Sedoreovirinae. The genome of BTV is 10 segmented dsRNA that codes for 7 structural and 4 nonstructural proteins, of which VP2 was reported to be serotype-specific and a major antigenic determinant. Objective: It is important to know the circulating serotypes in a particular geographical location for effective control of the disease. The present study unravels the molecular evolution of the circulating BTV serotypes during 2014-2018 in Telangana and Andhra Pradesh states of India. Methods: Multiple sequence alignment with available BTV serotypes in GenBank and phylogenetic analysis were per-
\end{abstract}

formed for the partial VP2 sequences of major circulating BTV serotypes during the study period. Results: The multiple sequence alignment of circulating serotypes with respective reference isolates revealed variations in antigenic VP2. The phylogenetic analysis revealed that the major circulating serotypes were grouped into eastern topotypes (BTV-1, BTV-2, BTV-4, and BTV-16) and Western topotypes (BTV-5, BTV-12, and BTV-24). Conclusion: Our study strengthens the need for development of an effective vaccine, which can induce the immune response for a range of serotypes within and in between topotypes.

(c) 2020 S. Karger AG, Basel

\section{Introduction}

Bluetongue (BT) is an economically important noncontagious, infectious, hemorrhagic disease of ruminants. It is caused by bluetongue virus (BTV) that belongs to the genus Orbivirus of family Reoviridae and subfam- karger@karger.com

www.karger.com/int

Karger ${ }^{\prime}=$
(C) 2020 S. Karger AG, Basel

Department of Veterinary Microbiology an
College of Veterinary Science, PVNR TVU

Rajendranagar, Hyderabad 500030 (India)

kalyaniputty@gmail.com 
ily Sedoreovirinae [1]. The transmission of BTV is mainly by the bite of a Culicoides midge [2]; however, there were reports indicating transmission by direct contact [3, 4] or through the transplacental route [5]. BT was considered as an emerging disease and listed by the World Organisation for Animal Health (OIE) as a "Notifiable Disease" [6]. Currently, 29 distinct serotypes of BTV are reported to be circulating geographically [7-9]. BT is endemic in India with a total of 24 serotypes reported; the majority of the outbreaks were reported from southern states in Peninsular India [10].

BTV genome is made up of 10 linear segments of double-stranded ribonucleic acid (dsRNA), enclosed within a three-layered icosahedral protein capsid. They encode for 11 distinct proteins, which include 7 structural proteins (VP1-VP7) and 4 nonstructural proteins (NS1, NS2, NS3/NS3A, and NS4) [11-13]. The outer capsid of BTV is made of VP2 and VP5 proteins, which are encoded by segments 2 and 6 , respectively $[14,15]$. These 2 proteins are primarily involved in cell attachment and entry during the early stages of infection and are known to elicit neutralizing antibodies. In particular, the VP2 gene contains the epitopes that bind to neutralizing antibodies generated during infection of the mammalian host and is the main determinant of the virus serotype [16].

The variations in the sequence of segment 2 and of its translated protein VP2 correlate with the BTV serotype [16]. The genome segments of BTV can be exchanged between different serotypes, and all segments can reassort independently [17]. The genome segments of most BTV isolates can be grouped into either the major "eastern" or "Western" topotypes. The major eastern group includes isolates from China, South Asia, Southeast Asia, and Australia, while the Western group includes viruses from America, Africa, Europe, and the Middle East [18]. Control of the disease is mainly challenging because of the occurrence of multiple serotypes and the presence of antigenic diversity within serotypes. There is a requirement for continuous identification and characterization of circulating serotypes/topotypes to overcome the challenges and to design an efficient vaccine strategy. The present study describes the molecular evolutionary patterns of the major circulating serotypes of BTV isolated during 20142018 in Telangana and Andhra Pradesh states of India.

\section{Materials and Methods}

\section{Sample Collection}

Heparinized blood was collected from BT-suspected cases exhibiting typical symptoms such as high fever, frothy salivation, na- sal discharges, oral ulcers, and torticollis. A total of 272 samples were collected from outbreaks reported during 2014-2018 in Telangana and Andhra Pradesh states of India. The majority of the suspected animals were not vaccinated with the available penatavalent inactivated vaccine against BT.

\section{Virus Isolation}

Lysed blood cells collected from suspected animals were directly inoculated to $\mathrm{KC}$ (Culicoides sonorensis) cells followed by passaging at least thrice in BHK-21 cells and observed for cytopathic changes. In this study, we characterized the isolates of 7 major circulating serotypes in Telangana and Andhra Pradesh, India, isolated during 2014-2018. These serotypes include BTV-1 (06MNB/2016),BTV-2(NLG1954/2014),BTV-4(KUR1413/2018), BTV-5 (WGL1057/2014), BTV-12 (KUR1481/2018), BTV-16 (KRL2/2017), and BTV-24 (WGL1065/2014).

\section{RNA Isolation and cDNA Synthesis}

The dsRNA of BTV was extracted from the cells infected with the respective serotype of BTV using TRIZOL ${ }^{\circledR}$ reagent (Ref: 15596018; Ambion $^{\circledR}$ ) as per the protocol described by the manufacturer. The segments of the dsRNA were verified by running $1 \%$ agarose gel and analyzed under the UV Gel Documentation system (UVITECH). The cDNA synthesis was carried out using $1 \mu \mathrm{g}$ of dsRNA as the template and random hexamers as the primer from the PrimeScript ${ }^{\mathrm{TM}} 1$ st strand cDNA Synthesis kit (Cat No. $6110 \mathrm{~A} ; \mathrm{TaKaRa}^{\circledR}$ ) as per the protocol described by the manufacturer.

\section{PCR Amplification and Sequencing}

The PCR was performed targeting the VP2 gene of BTV with cDNA as the template and serotype-specific primer pairs targeting Seg-2 as described previously $[10,19,20]$ using Emerald Amp ${ }^{\circledR}$ GT PCR Master Mix (TaKaRa) as per the protocol described by the manufacturer. Briefly, the PCR was carried out with an initial denaturation at $94^{\circ} \mathrm{C}$ for $3 \mathrm{~min}, 35 \mathrm{cycles}$ each of denaturation at $94^{\circ} \mathrm{C}$ for $30 \mathrm{~s}$, primer annealing at $55^{\circ} \mathrm{C}$ for $30 \mathrm{~s}$ depending on the melting temperature of the respective primers, extension at $72^{\circ} \mathrm{C}$ for $1 \mathrm{~min}$, and final extension at $72^{\circ} \mathrm{C}$ for $10 \mathrm{~min}$. PCR products were purified using XcelGen ${ }^{\circledR}$ PCR Purification MiniKit as per the manufacturer's instructions and sequenced at the sequencing facility, Xcelris Labs Ltd., Gujarat, using VP2 gene-specific primers used for amplification. The sequences were compared with the reference sequence using ClustalW, and the mutations were verified with the peaks from the chromatogram using Chromas v.2.0. The sequences were corrected if there is variation with peaks from the chromatogram using Lasergene software (DNASTAR Inc., Madison, WI, USA).

\section{Multiple Sequence Alignment and Phylogenetic Analysis}

After retrieving the sequences from the chromatogram, the sequences were aligned against the other isolates from the NCBI database for the respective serotypes using ClustalW from MEGA7. The percentage nucleotide sequence identity was compared with NCBI BLAST for the respective serotypes. Furthermore, the amino acid sequence of the 7 serotypes was aligned with the respective isolates to understand the variations in the protein sequence. The unrooted phylogenetic tree was generated using the neighborjoining method, tamura-3-parameter model, and bootstrap value of 1,000 in MEGA7 [21]. 
Fig. 1. PCR amplification of the partial VP2 gene from 7 serotypes of BTV. a Lanes 1, 4, $7,11,14$, and 17 show the amplification product of the BTV serotypes BTV-1 (06MNB/2016; 1,180 bp), 2 (NLG1954/ 2014; 1,167 bp), 16 (KRL2/2017; 1,196 bp), 12 (KUR1481/2018; 752 bp), 4 (KUR1413/ 2018; 465 bp), and 5 (WGL1057/2014; 445 bp), respectively, analyzed in the current study. Lanes 2, 5, 8, 12, 15, and 18 are positive control for the BTV serotypes BTV-1, $2,16,12,4$, and 5 , respectively. Lanes 3,6 , $9,13,16$, and 19 are negative control for the BTV serotypes BTV-1, 2, 16, 12, 4, and 5, respectively. Lanes 10 and 20 are $1 \mathrm{kbp}$ and 100 bp DNA markers, respectively. b Lane 4 is BTV-24 (WGL1065/2014; 320 bp) isolated in the current study, while lanes 1 and 2 are positive and negative controls, respectively, of BTV-24. Lane 3 is the 100 bp DNA marker. BTV, bluetounge virus.

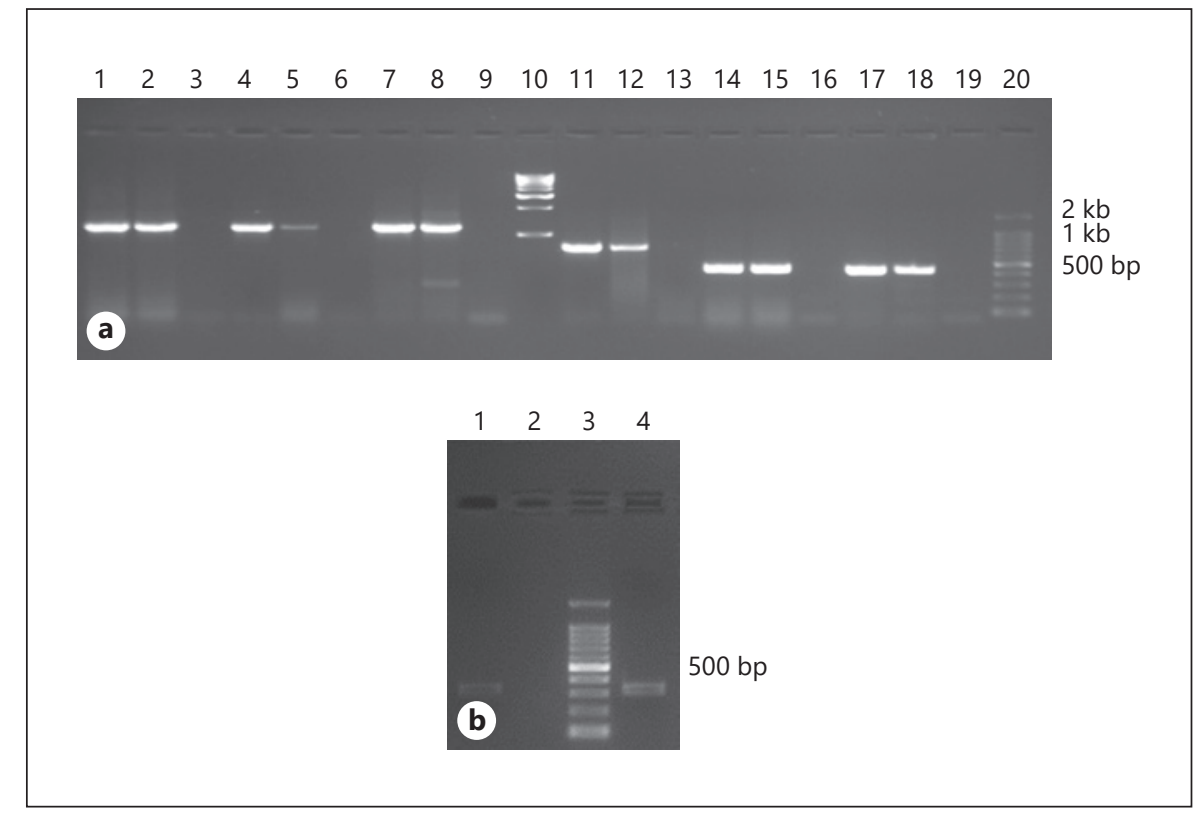

\section{Results}

PCR Amplification of the Partial VP2 Gene of BTV

The dsRNA of the respective 7 serotypes of BTV were analyzed on $1 \%$ agarose gel after isolation for confirmation of purity and intactness. Online suppl. Figure 1 (see www.karger.com/doi/10.1159/000512131 for all online suppl. material) shows the segmented nature of the BTV dsRNA for all the 7 serotypes, and the dsRNA was pure and intact. The cDNA was synthesized and PCR was performed as mentioned in the methods and was analyzed on $1 \%$ agarose gel. Amplicons generated were of the specific size corresponding to each set of primer pairs specific to a particular BTV serotype, that is, $1,180 \mathrm{bp}$ for BTV-1, 1,167 bp for BTV-2, 1,196 bp for BTV-16, 752 bp for BTV-12, 465 bp for BTV-4, 445 bp for BTV-5, and 320 bp for BTV-24 (Fig. 1).

\section{Sequencing and BLAST Analysis}

The sequences were extracted from the chromatogram for the respective 7 serotypes, and the sequences were submitted in the GenBank of the NCBI database. The accession numbers for the same are BTV-1 (MN651992), BTV-2 (MN651993), BTV-4 (MN651994), BTV-5 (MN651995), BTV-12 (MN651996), BTV-16 (MN651997), and BTV-24 (MN651998).

BLASTN analysis for the sequence of respective 7 serotypes shows that they align with the VP2 sequences of the previously published database. However, there is a nucleotide variation between the isolates of the same serotype. The nucleotide similarity as a measure of percentage of identity was noted to understand the degree of relatedness.

The percent identity for BTV-1 ranged from 96.9 to $99.26 \%$ for Indian isolates and $<95 \%$ for isolates from Australia (KM099523; KM099531; KM099532; KM099533; KM099534; and AJ585178), China (KC879616), Malaysia (AJ585116), Greece (AJ585121; JN635334; and KP821007), South Africa (AJ585122), Sudan (AJ585117), Nigeria (AJ585118), and Cameroon (AJ585119). The percent identity for BTV-2 ranged from 96.9 to $99.64 \%$ for Indian isolates and $<95 \%$ for isolates from Taiwan (AY493687), Australia (MF3844476; MF384475; MF384474; JQ240322; and JQ086242), Japan (AB686224), South Africa (AJ585123), USA (M21946), Sudan (AJ585155), Nigeria (AJ585153), Corsica (AJ585154; AF356601), Sicily (AJ585158; AJ585159; and AJ585160), and Sardinia (AJ585161; AJ585162).

The percent identity for BTV-4 ranged from 97.7 to 99\% for isolates from India and China (JX560414) and $<95 \%$ for isolates from South Africa (AJ585125), Greece (KP821055), Turkey (AJ585165), Italy (DQ191279), Argentina (AJ585169), Egypt (KP821047), France (KY654329), Hungary (KP268815), Sudan (AJ585166), and Corsica (AY839945). Furthermore, the percent identity with BTV-24 isolates of China (KT945048), Israel (JN162683; JN162682), and South Africa (MG255590) shows $73.35,77,77.82$, and $78.23 \%$ respectively.
10

Intervirology 2021;64:8-15 DOI: $10.1159 / 000512131$
Thota et al. 
The percent identity for BTV -5 ranged from 96 to $99.5 \%$ for isolates from India, China (KT945043; KT945044; KT945045; and KT945050), Australia (MG924987), South Africa (MG255450; AJ585126; JX272570), and Cameroon isolate (AJ585181). The percent identity for BTV-12 ranged from 95 to $99.5 \%$ for isolates from India, China (KP195138; KP221199), South Africa (JX272500; AJ585133; and KP821100), Kenya (AJ585185), Japan (AB686216), and Taiwan (GU390659) and $<95 \%$ for isolates from South Africa(MG255670;MG255680), Israel(KT946759; KT946760; and KT946761), USA (KX164080; KX164090), and France (KC633278).

The percent identity for BTV-16 ranged from 95.29 to 98.5\% for isolates from India, Japan (AB686220; AB686226; and AB686225), Greece (KP820989; KP820990; and AM773709), China (KP195134; KP195134), Israel (KP820992), UK (KP820985; KP820986; and KP820987), Turkey (AJ585146; AJ585147; and AJ585148), UK (KP820988), Italy (KF387522; MH990434; MH990424; and MK014493), and South Africa (AJ585137) and $<95 \%$ for isolates from Australia (MF384481; MF384480) and Indonesia (AJ585151). The percent identity for BTV-24 ranged from 95 to $98.2 \%$ for isolates from China (KT945048; KT945049), South Africa (AJ585145; JX272370; and MG255590), Israel (JN162682; JN162683; JN162684; JN162685; and JN162686) and $<95 \%$ for isolates from USA (KX164150) and France (HQ222823; JN003581; and KC633277). Furthermore, the percent identity with BTV-4 isolates of Israel (KP821060) was 94.95\%.

\section{Multiple Sequence Alignment and Phylogenetic Analysis}

The reference isolates from the BLAST analysis were collected randomly from different geographical locations. The sequence of each of the 7 serotypes was aligned against the respective reference isolates. Furthermore, the amino acid sequence alignment of 7 serotypes with respective reference isolates shows variations in the protein sequence (Table 1). The phylogenetic trees were constructed by the neighbor-joining method using the Tamura 3-parameter model for the 7 serotypes. BTV-1 isolate (MN651992) was grouped closely with isolates from India, Greece, China, Malaysia, and Australia, whereas it is distantly related to isolates from South Africa, Nigeria, Sudan, and Cameroon (Fig. 2a). BTV-2 isolate (MN651993) was grouped closely with isolates from India, Taiwan, Australia, and Japan, whereas it is distantly related to isolates from South Africa, Corsica, Sardinia, Sicily, Nigeria, and Sudan (Fig. 2b). BTV-4 isolate
(MN651994) was grouped closely with isolates from India and China, whereas it is distantly related to isolates from South Africa, Greece, Turkey, Italy, France, Egypt, Sudan, Corsica, and Argentina (Fig. 2c). BTV-5 isolate (MN651995) was grouped closely with isolates from India, China, South Africa, and Cameroon (Fig. 2d). BTV12 isolate (MN651996) was grouped closely with isolates from India, China, Japan, and Taiwan, whereas it is distantly related to isolates from South Africa, Israel, USA, and France (Fig. 2e). BTV-24 isolate (MN651998) was grouped closely with isolates from Israel, China, and South Africa, whereas it is distantly related to isolates from the USA and France (Fig. 2f). BTV-16 isolate (MN651997) was grouped closely with isolates from India, Japan, Greece, China, Israel, UK, Turkey, Italy, and South Africa, whereas it is distantly related to isolates from Australia and Indonesia (Fig. 2g).

Table 1. Amino acid variation of 7 serotypes with respective reference isolates

\begin{tabular}{lll}
\hline Serotype & Reference isolate & $\begin{array}{l}\text { Amino acid } \\
\text { change* }\end{array}$ \\
\hline BTV-1E (06MNB/2016) & KC751420 India & V242I \\
\hline BTV-2E (NLG1954/2014) & KP339165 India & N511S \\
\hline BTV-4W (KUR1413/2018) & KY947351 India & I246V \\
\hline BTV-5W (WGL1057/2014) & KT945045 China & S577P \\
\hline BTV-12W (KUR1481/2018) & MF615238 India & N581D \\
\hline BTV-16E (KRL2/2017) & KC751424 India & V182A \\
& & Q233R \\
& & D320 N \\
& & G418R \\
\hline BTV-24W (WGL1065/2014) & KT945048 China & I820F
\end{tabular}

* The amino acid change is represented as V242I, where V represents the amino acid from the reference isolate, 242 represents the position of amino acid change on the VP2 gene, and I represents the changed amino acid in the current isolate. BTV, bluetounge virus.

Fig. 2. Phylogenetic analysis of 7 circulating serotypes of BTV isolated during 2014-2018 in India: BTV-106MNB/2016(MN651992) (a);BTV-2NLG1954/2014(MN651993)(b);BTV-4KUR1413/2018 (MN651994) (c); BTV-5 WGL1057/2014 (MN651995) (d); BTV12 KUR1481/2018 (MN651996) (e); BTV-24 WGL1065/2014 (MN651998) (f); and BTV-16 KRL2/2017 (MN651997) (g). BTV, bluetounge virus.

(For figure see next pages.) 

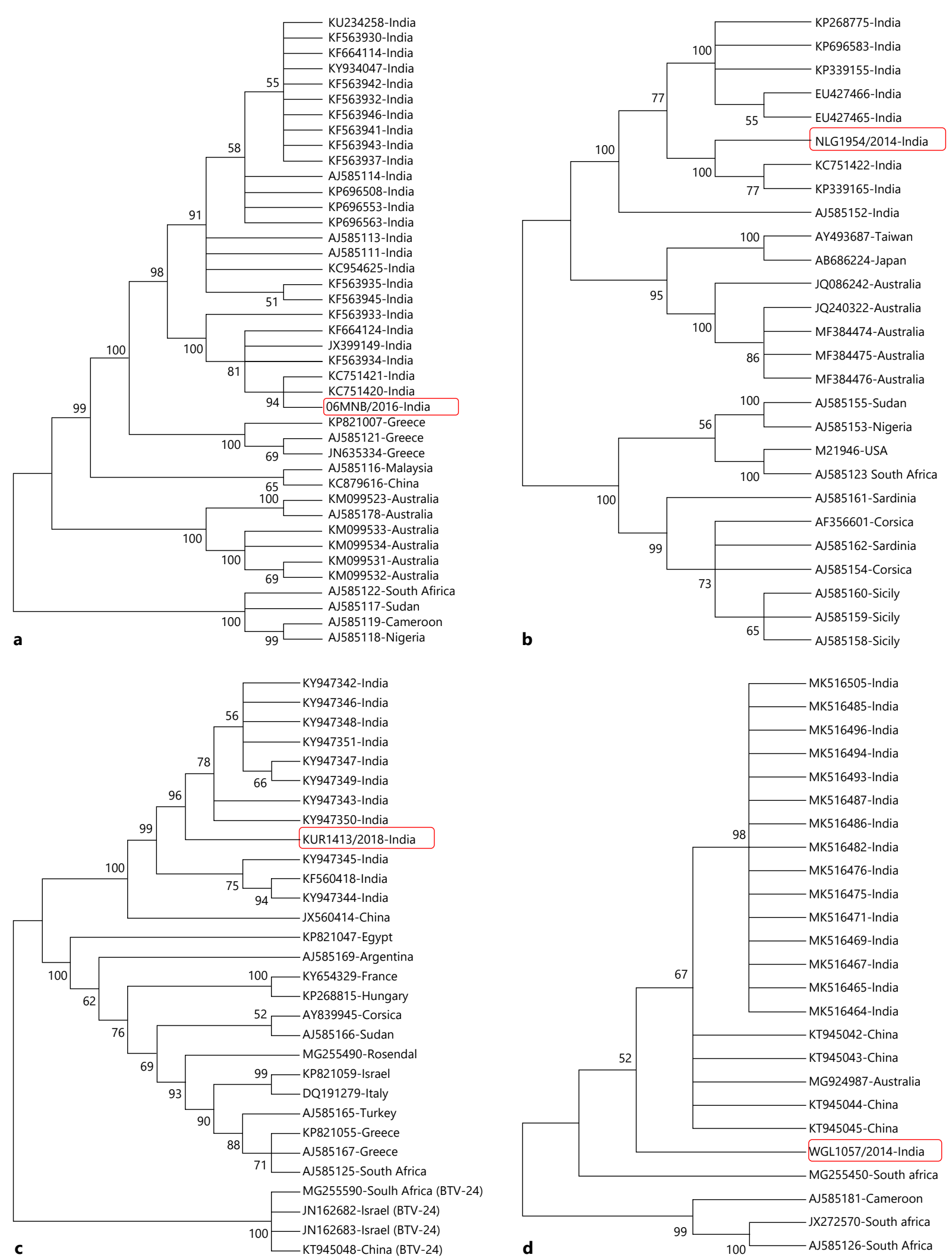

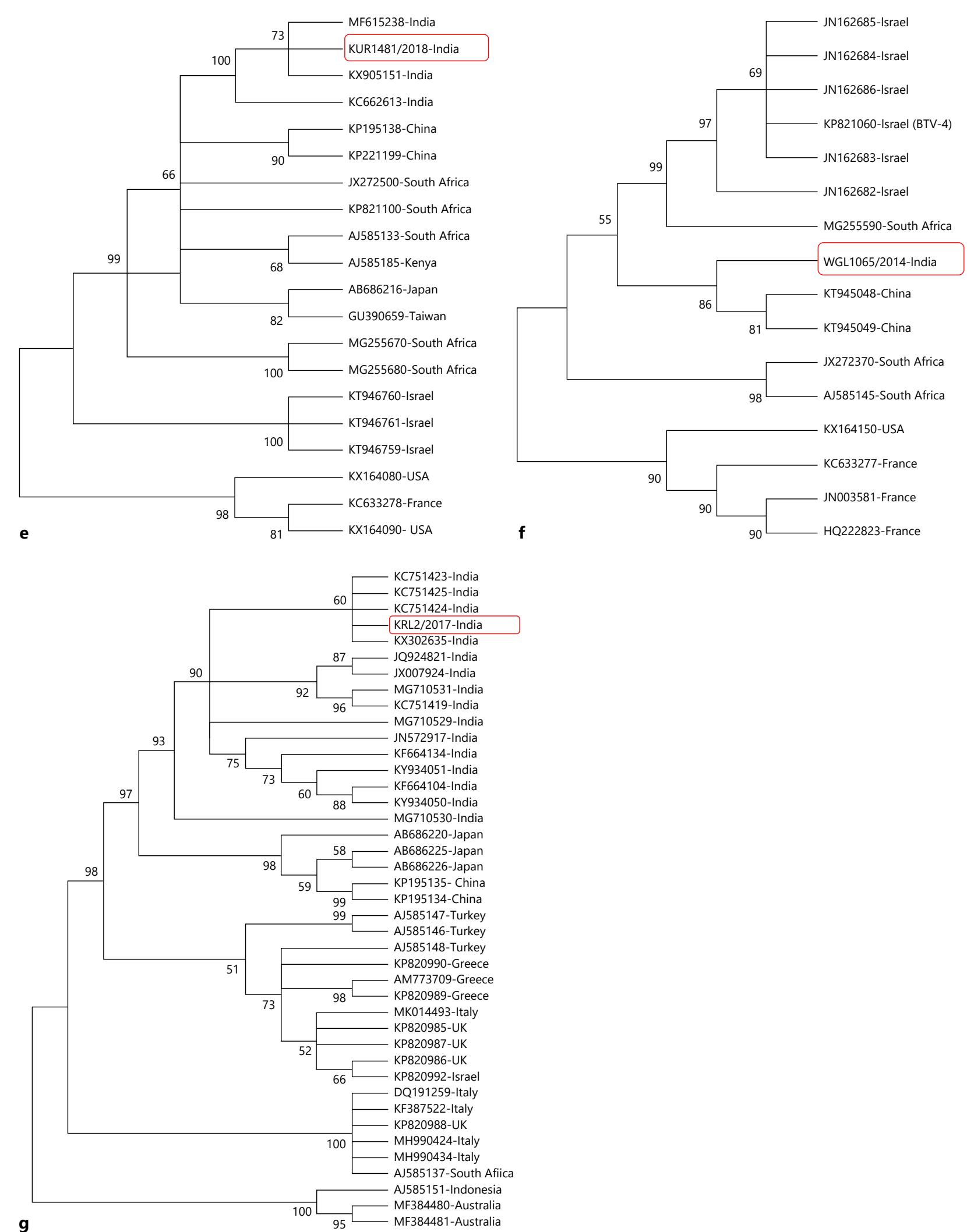

2

Molecular Epidemiology of Bluetongue Virus
Intervirology 2021;64:8-15

DOI: $10.1159 / 000512131$ 


\section{Discussion}

BT exists as 29 distinct serotypes geographically [7-9], of which 24 serotypes were reported in India, either by virus isolation or serology $[19,22,23]$. It is important to understand the patterns of molecular evolution in a particular area as the occurrence of multiple serotypes and the presence of antigenic diversity within serotypes make the disease control more challenging. The present study has been taken up with a challenge to unravel the molecular evolutionary patterns of major circulation serotypes of BTV isolated during 2014-2018 in the regions of Telangana and Andhra Pradesh states of India.

In the present study, the highly variable VP2 region was selected for understanding BTV molecular epidemiology. VP2 was reported to be serotype-specific and a major antigenic determinant of BTV $[24,25]$. The VP2 region is highly variable among BTV serotypes with interserotype variability ranging from 29 to $59 \%$ with respect to nucleotide composition, while the deduced amino acid sequence of VP2 varied from 22.4 to $73 \%$ [26, 27]. A few similarities were observed in the VP2 region between different BTV serotypes. These regions were hypothesized to be antigenically important, playing a role in the neutralizing antibody response $[26,28,29]$. The partial VP2 region was amplified and sequenced from the cDNA using the primers described previously $[10,19,20]$. The multiple sequence alignment for each respective serotype revealed amino acid and nucleotide variations. The VP2 region is highly variable, and there were reports suggesting high level of variations in nucleotide and amino acid sequences within the serotype and in between BTV serotypes [26, 27, 30].

For efficient preventive and control strategies to be implemented, it is crucial to understand the circulating serotypes, especially for BTV that circulates as multiple serotypes. With high sheep population density, congenial climatic conditions for Culicoides propagation, and susceptible sheep breeds, Southern Peninsular India witnesses a majority of BTV outbreaks [31]. Ranking 1st in sheep population in the country, Telangana and Andhra Pradesh states of Southern India are always a point of concern with respect to BT disease. In the current study, BTV isolates from these 2 states isolated from outbreaks during the years 2014-2018 were evaluated to understand the molecular evolutionary patterns. The phylogenetic analysis revealed that BTV-1, BTV-2, BTV-4, and BTV-16 formed close proximity with eastern topotypes and were distantly related to Western topotypes. Previous reports also suggest that the Indian isolates of BTV-1, BTV-2, BTV-4, and BTV-16 were in close proximity with eastern topotypes [20, 27, 32-34]. Further- more, for BTV-4, we noticed a nucleotide similarity of around 73.35-78.23\% with BTV-24 isolates from China, Israel, and South Africa, but distantly related to the BTV-24 isolate used in the current study. The similar kind of observation was reported previously [26], where they described this phenomenon as different serotypes that might have evolved from a common ancestral gene. However, the serotypes BTV-5, BTV-12, and BTV-24 were observed to be in close proximity with Western topotypes. This was not surprising as the previous reports also categorized these serotypes under Western topotypes $[19,23,35,36]$. The BTV24 serotype also shared the close proximity with BTV-4 isolate from Israel. Furthermore, we have noticed the same observations based on the percent nucleotide identity analysis in BLASTN.

In conclusion, the study reveals that the serotypes circulating in Telangana and Andhra Pradesh regions of India during 2014-18 share an evolutionary relationship with eastern topotypes (BTV-1, BTV-2, BTV-4, and BTV-16) and Western topotypes (BTV-5, BTV-12, and BTV-24).

\section{Statement of Ethics}

The study involves neither human nor animal experimentation; hence, no formal approval was needed. This work has been performed in accordance with standard operating procedures adopted by the Department of Veterinary Microbiology and Biotechnology, PVNR TVU, Hyderabad, India.

\section{Conflict of Interest Statement}

The authors confirm no conflicts of interest arising from the work. All the authors accepted the order of authorship.

\section{Funding Sources}

The authors acknowledge the ICAR-All India Network Project on Bluetongue and DBT (BT/IN/Indo-UK/FADH/46/SM/2013; BT/PR9711/ADV/90/158/2013) for funding the study.

\section{Author Contributions}

T. Ravali collected the samples and performed the experiments. Vishweshwar Kumar Ganji analyzed the data and wrote the article. M. Sharanya, B. Bhagyalakshmi, and Y. Krishnajyothi performed the experiments. Y. Narasimha Reddy conceived the study. Rao PP, Sushila Maan, NS Maan, Diwakar Hemadri, and KP Singh analyzed the data. Putty Kalyani conceived and designed the study, analyzed the data, and wrote the manuscript.
Thota et al. 


\section{References}

1 ICTV. Reoviridae - dsRNA Viruses - dsRNA Viruses (2011) - International Committee on Taxonomy of Viruses (ICTV) [Internet]. 2019 [cited 2019 Nov 8]. Available from: https: //talk.ictvonline.org/ictv-reports/ictv_ 9th_report/dsrna-viruses-2011/w/dsrna_viruses/188/reoviridae

2 Mellor PS, Boorman J. The transmission and geographical spread of African horse sickness and bluetongue viruses. Ann Trop Med Parasitol. 1995;89(1):1-15.

3 Batten C, Darpel K, Henstock M, Fay P, Veronesi E, Gubbins S, et al. Evidence for transmission of bluetongue virus serotype 26 through direct contact. PLoS One. 2014 May; 9(5):e96049.

4 Bréard E, Schulz C, Sailleau C, BernelinCottet C, Viarouge C, Vitour D, et al. Bluetongue virus serotype 27: experimental infection of goats, sheep and cattle with three BTV27 variants reveal atypical characteristics and likely direct contact transmission BTV-27 between goats. Transbound Emerg Dis. 2018 Apr;65(2):e251-63.

5 Saegerman C, Bolkaerts B, Baricalla C, Raes M, Wiggers L, de Leeuw I, et al. The impact of naturally-occurring, trans-placental bluetongue virus serotype- 8 infection on reproductive performance in sheep. Vet J. 2011 Jan; 187(1):72-80

6 OIE. OIE-Listed diseases 2019: OIE - World Organisation for Animal Health [Internet]. 2019 [cited 2019 Nov 8]. Available from: https: //www.oie.int/animal-health-in-theworld/oie-listed-diseases-2019/.

7 Hofmann MA, Renzullo S, Mader M, Chaignat V, Worwa G, Thuer B. Genetic characterization of toggenburg orbivirus, a new bluetongue virus, from goats, Switzerland. Emerg Infect Dis. 2008 Dec;14(12):1855-61.

8 Maan S, Maan NS, Nomikou K, Batten C, Antony F, Belaganahalli MN, et al. Novel bluetongue virus serotype from Kuwait. Emerg Infect Dis. 2011;17(5):886-9.

9 Zientara S, Sailleau C, Viarouge C, Höper D, Beer M, Jenckel M, et al. Novel bluetongue virus in goats, Corsica, France, 2014. Emerg Infect Dis. 2014 Dec;20(12):2123-5.

10 Reddy YV, Krishnajyothi Y, Susmitha B, Devi BV, Brundavanam Y, Gollapalli SR, et al. Molecular typing of bluetongue viruses isolated over a decade in South India. Transbound Emerg Dis. 2016 Oct;63(5):e412-8.

11 Verwoerd DW, Louw H, Oellermann RA. Characterization of bluetongue virus ribonucleic acid. J Virol. 1970 Jan [cited 2019 Nov 8]; 5(1):1-7.

12 Mertens PP, Brown F, Sangar DV. Assignment of the genome segments of bluetongue virus type 1 to the proteins which they encode. Virology. 1984;135(1):207-17.
13 Ratinier M, Caporale M, Golder M, Franzoni G, Allan K, Nunes SF, et al. Identification and characterization of a novel non-structural protein of bluetongue virus. PLoS Pathog. 2011 Dec;7(12):e1002477.

14 Roy P, Noad R. Bluetongue virus assembly and morphogenesis. Curr Top Microbiol Immunol. 2006;309:87-116.

15 Rao PP, Hegde NR, Singh KP, Putty K, Hemadri D, Maan NS, et al. Bluetongue: aetiology, epidemiology, pathogenesis, diagnosis and control. In: Emerging and Re-emerging Infectious diseases of livestock. Springer International Publishing; 2017. p. 3-54.

16 Pal Singh K, Mertens P, Diprose J, Maan S, Singh K, Attoui $\mathrm{H}$, et al. Bluetongue virus replication, molecular and structural biology; 2004

17 Shaw AE, Ratinier M, Nunes SF, Nomikou K, Caporale M, Golder M, et al. Reassortment between two serologically unrelated bluetongue virus strains is flexible and can involve any genome segment. J Virol. 2013 Jan;87(1): 543-57.

18 Maan S, Maan NS, van Rijn PA, van Gennip RG, Sanders A, Wright IM, et al. Full genome characterisation of bluetongue virus serotype 6 from the Netherlands 2008 and comparison to other field and vaccine strains. PLoS One. 2010 Apr;5(4):e10323.

19 Krishnajyothi Y, Maan S, Kandimalla K, Maan NS, Tutika RB, Reddy YV, et al. Isolation of bluetongue virus 24 from India: an exotic serotype to Australasia. Transbound Emerg Dis. 2016 Aug;63(4):360-4.

20 Reddy YV, Susmitha B, Patil S, Krishnajyothi Y, Putty K, Ramakrishna KV, et al. Isolation and evolutionary analysis of Australasian topotype of bluetongue virus serotype 4 from India. Transbound Emerg Dis. 2018 Apr; 65(2):547-56.

21 Tamura K, Stecher G, Peterson D, Filipski A, Kumar S. MEGA6: molecular evolutionary genetics analysis version 6.0. Mol Biol Evol. 2013 Dec;30(12):2725-9.

22 Sairaju V, Susmitha B, Rao PP, Hegde NR, Meena K, Reddy YN. Type-specific seroprevalence of bluetongue in Andhra Pradesh, India, during 2005-2009. Indian J Virol. 2013 Dec;24(3):394-7.

23 Hemadri D, Maan S, Chanda MM, Rao PP, Putty K, Krishnajyothi Y, et al. Dual infection with bluetongue virus serotypes and firsttime isolation of serotype 5 in India. Transbound Emerg Dis. 2017 Dec;64(6):1912-7.

24 Huismans H, Erasmus BJ. Identification of the serotype-specific and group-specific antigens of bluetongue virus. Onderstepoort J Vet Res. 1981 Jun [cited 2019 Nov 8];48(2):51-8.

25 Roy P. Functional mapping of bluetongue virus proteins and their interactions with host proteins during virus replication. Cell Biochem Biophys. 2008 Mar;50(3):143-57.
26 Maan S, Maan NS, Samuel AR, Rao S, Attoui $\mathrm{H}$, Mertens PP. Analysis and phylogenetic comparisons of full-length VP2 genes of the 24 bluetongue virus serotypes. J Gen Virol. 2007 Feb;88(Pt 2):621-30.

27 Maan S, Maan NS, Samuel AR, O'hara R, Meyer AJ, Rao S, et al. Completion of the sequence analysis and comparisons of genome segment 2 (encoding outer capsid protein VP2) from representative isolates of the 24 bluetongue virus serotypes. Vet Ital. 2004 Oct-Dec;40(4):484-8

28 Gould AR, Hyatt AD, Eaton BT. Morphogenesis of a bluetongue virus variant with an amino acid alteration at a neutralization site in the outer coat protein, VP2. Virology. 1988 Jul; 165(1):23-32.

29 Jyothi JS, Putty K, Patil SR, Reddy YN. In-silico approach to determine the possibility of a recombinant broad-spectrum vaccine for bluetongue disease. Indian J Anim Res. 2018; 53:1229-33.

30 Maan S, Maan NS, Belaganahalli MN, Kumar A, Batra K, Rao PP, et al. Genome sequence of bluetongue virus type 2 from India: evidence for reassortment between outer capsid protein genes. Genome Announc. 2016;3(2).

31 Rao P, Krishnajyoth Y, Reddy V, Susmitha B, Reddy H, Sreenivasulu D, et al. A decade of research on bluetongue virus in Andhra Pradesh, a Southern state of India. Vet Ital. 2016 Jul;52(3-4):299-304.

32 Biswas SK, Chand K, Rehman W, Reddy YN, Mondal B. Segment-2 sequencing and crossneutralization studies confirm existence of a neutralization resistant VP2 phenotypic variant of bluetongue virus serotype 1 in India. Vet Microbiol. 2015 Apr;176(3-4):358-64.

33 Hemadri D, Sanyal A, Tosh C, Venkataramanan R, Pattnaik B. Serotype C foot-andmouth disease virus isolates from India belong to a separate so far not described lineage. Vet Microbiol. 2003 Mar;92(1-2):25-35.

34 Saxena A, Biswas SK, Chand K, Naskar J, Chauhan A, Mohd G, et al. Genetic and phylogenetic analysis of the outer capsid protein genes of Indian isolates of bluetongue virus serotype-16. Vet World. 2018 Aug;11(8): 1025-9.

35 White JR, Williams DT, Wang J, Chen H, Melville LF, Davis SS, et al. Identification and genomic characterization of the first isolate of bluetongue virus serotype 5 detected in Australia. Vet Med Sci. 2019 May;5(2):129-45.

36 Maan S, Kumar A, Gupta AK, Dalal A, Chaudhary D, Gupta TK, et al. Concurrent infection of bluetongue and peste-des-petitsruminants virus in small ruminants in Haryana State of India. Transbound Emerg Dis. 2018 Feb;65(1):235-9. 